\title{
Hypoxia in Abdominal Aortic Aneurysm Supports a Role for HIF-1 $\alpha$ and Ets-1 as Drivers of Matrix Metalloproteinase Upregulation in Human Aortic Smooth Muscle Cells
}

\author{
Olivia J. Erdozain ${ }^{a} \quad$ Susan Pegrum ${ }^{a} \quad$ Vivienne R. Winrow ${ }^{a} \quad$ Michael Horrocks ${ }^{a}$ b \\ Cliff R. Stevens ${ }^{a}$ \\ ${ }^{a}$ Department for Health, University of Bath, and ${ }^{b}$ Department of Surgery, Royal United Hospital, Bath, UK
}

\section{Key Words}

Abdominal aortic aneurysm $\cdot$ Hypoxia $\cdot$ Matrix metalloproteinase $\cdot$ Hypoxia-inducible factor- $1 \alpha \cdot$ Ets-1 transcription factor

\begin{abstract}
Background/Aims: We sought to determine whether hypoxia is an initiating factor in the matrix metalloproteinase-2 (MMP-2) up-regulation observed in abdominal aortic aneurysm (AAA) and whether hypoxia-inducible factor- $1 \alpha$ (HIF$1 \alpha$ ) or Ets-1 are mediating factors. Methods: Human AAA and normal aorta were analysed for MMP-2, HIF-1 $\alpha$ and Ets-1 by immunohistochemistry. Human aortic smooth muscle cell (HASMC) cultures exposed to experimental hypoxia were analysed for hypoxia-induced proteins using gelatin zymography and immunoblotting. Multiplex PCR was used to detect MMP-1, membrane-type (MT)-MMP-1, MMP-2, MMP-3, MMP-7 and MMP-9. Results: AAA tissues expressed HIF-1 $\alpha$, MMP-2 and Ets-1 strongly within smooth muscle cells and inflammatory infiltrate of the tunica media. Up-regulated MMP-2 was detected in hypoxia-exposed HASMC $(p<$ 0.05), with MMP-9 elevations after exposure to sequential $\mathrm{O}_{2}$ decreases $(p<0.05)$. Immunoblotting confirmed HIF- $1 \alpha$, Ets1 , VEGF and MMP-2 are up-regulated in HASMC exposed to hypoxia $(p<0.05)$, while transcription for MMP-1, MT-MMP-1,
\end{abstract}

MMP-9, MMP-2 and MMP-7 $(p<0.05)$ increased in hypoxic HASMCs. Conclusion: Hypoxia facilitates HIF- $1 \alpha$, Ets- 1 and VEGF up-regulation in addition to driving enhanced secretion of MMP-2 and MMP-9 by HASMC. Enhanced transcription of factors relevant to aneurysmal disease in hypoxia indicates possible roles in disease progression and potential targets for therapeutic intervention.

Copyright $\odot 2010$ S. Karger AG, Basel

\section{Introduction}

The abdominal aortic aneurysm (AAA) is a permanent dilation of the arterial wall that, if left untreated, leads to rupture and fatal bleeding into the retroperitoneal cavity. About $5 \%$ of men over the age of 50 will develop an AAA. If rupture occurs, there is an overall mortality rate of over $80 \%$ accounting for nearly $1.5 \%$ of deaths in men over 65 [1]. Increased matrix metalloproteinase (MMP) activity is implicated in aneurysm formation through elastin destruction and collagen degradation. MMP-2 is thought to be important in the initiation of AAA, whilst MMP-9 has a significant role in early and late aneurysms [2]. The mechanism for AAA induction has not been fully elucidated, but one of the candidates may be arterial wall hypoxia, which has been investigated in conditions such as

\section{KARGER}

Fax +41 613061234 E-Mail karger@karger.ch www.karger.com

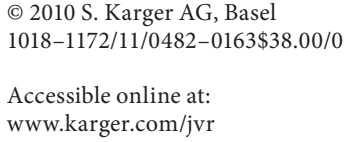

Dr. Cliff R. Stevens

Department for Health, University of Bath

Claverton Down

Bath, BA2 7AY (UK)

Tel. +44 1225383 835, Fax +44 1225383 847, E-Mail mpscrs@bath.ac.uk 
atherosclerosis, intimal hyperplasia and myointimal hyperplasia [3-9]. Animal models of AAA have demonstrated low oxygen tension in the aortic media [9]. Low oxygen tensions within the aortic media are said to alter vascular smooth muscle cell function leading to aortic degradation and potential aneurysm formation $[10,11]$. Studies have shown that hypoxia exists in vivo in aneurysms of patients [12-14]. It has been shown that intraluminal thrombus, a common feature of AAA, contributes to wall hypoxia and weakening $[13,15]$. The global oxygen sensor HIF-1 $\alpha$ responds to low tissue oxygen by up-regulating hypoxia responsive genes. Interestingly, studies in joint disease and cancer have demonstrated modulation of MMP by HIF$1 \alpha$ [16-18] and also that ets-1 transcription factor, present in endothelium, is induced by HIF [19]. Thus, HIF-1 $\alpha$ is a potential initiating factor in the pathway leading to MMP up-regulation in AAA. There is evidence to support this. It is known that pro-inflammatory TNF- $\alpha$ is elevated in the naïve ( $<50 \mathrm{~mm}$ diameter) AAA, possibly involved as an early event, and that HIF- $1 \alpha$ is up-regulated in response to TNF- $\alpha$ and inflammation [20-22]. Immunohistochemical analysis of the AAA wall showed expression of TNF- $\alpha$ mainly in regions of atheromatous change and macrophage infiltration with HIF-1 $\alpha$ being localised histologically to the vascular smooth muscle cells and the rupture site $[14,22,23]$. In addition to this, MMP-2 is known to be responsible for the extensive elastin destruction in the smaller AAA, and active MMP-2 secretion is promoted by raised TNF- $\alpha[2,24]$ possibly via its effect on the stabilisation of HIF- $1 \alpha$ targeting Ets-1.

We hypothesise that the hypoxia-induced MMP-2 activation in early aneurysm formation is mediated by a signalling cascade involving HIF- $1 \alpha$.

\section{Materials and Methods}

\section{Specimen Collection and Sample Preparation}

With local ethics approval, AAA tissue was obtained from 36 consented patients undergoing elective surgical repair. Proximal, body and distal regions were identified and excised from each and then 3 samples were taken per region, giving a total of 9 separate samples per aneurysm. Sections were taken from the most proximal and distal margins of the aneurysm as well as the dilated body of the sac (enlarged aorta) to represent different stages of AAA development. Normal tissue was obtained, with local ethics approval, from the aortic cuff of 12 pulseless renal transplant donors who showed no evidence of aortic disease.

\section{Immunohistochemistry}

Tissue samples were fixed in $0.9 \% \mathrm{NaCl}(10 \% \mathrm{v} / \mathrm{v})$ histological formaldehyde within $12 \mathrm{~h}$ of harvest and processed using a Hypercentre II Fibrowax ${ }^{\mathrm{TM}}$ embedding station (Shandon Inc., Pitts- burgh, Pa., USA). Sections (5 $\mu \mathrm{m})$ were de-paraffinised, then rehydrated in preparation for staining. Sections were evaluated using mouse monoclonal anti-human HIF-1 $\alpha$ (Abgene Ltd., Epsom, UK), mouse monoclonal anti-human MMP-2 (NeoMarkers Ltd., Fremont, Calif., USA) or rabbit polyclonal anti-human Ets-1 (Santa Cruz Inc., Heidelberg, Germany). The alkaline phosphataseconjugated avidin/biotin complex, anti-mouse or anti-rabbit $(\mathrm{ABC})$ kit and protocol were used for protein localisation (Vectastain ${ }^{\circledR}$ ABC-AP reagent, AK-5001; Vector Laboratories, Peterborough, UK). Monoclonal IgG1 was used as a negative control (Dako UK Ltd., Cambridgeshire, UK). Endogenous alkaline phosphatase was inhibited using Levamisole (SP-5000; Vector Laboratories). Sections were then incubated in naphthol AS-MX phosphate/fast red TR Fast ${ }^{\mathrm{TM}}$ substrate solution (Sigma-Aldrich Ltd., Dorset, UK). Since the control tissue utilised for immunohistochemistry was from normal renal transplant aortic cuff, any HIF-1 $\alpha$ presence could be due to cold ischaemia. Therefore, to address the potential confounding influence of storage conditions, a 24-hour study was performed, where 'normal' samples from the aneurysm margin were kept in either Hanks' balanced salt solution, or dry in tubes at $4^{\circ} \mathrm{C}$. Samples of these tissues were fixed sequentially from 0 to $24 \mathrm{~h}$. No HIF-1 $\alpha$ expression was observed throughout the $24 \mathrm{~h}$, although background staining increased over the 24-hour period.

Isolation and Culture of Normal Human Aortic Smooth Muscle Cells

Explants of approximately $2-3 \mathrm{~mm}^{2}$ were cut from the tunica media and cultured in Dulbecco's modified Eagle's medium with $10 \%$ foetal calf serum, L-glutamine (2\%), penicillin and streptomycin (10,000 IU/ml; Invitrogen Ltd., Paisley, UK) at $37^{\circ} \mathrm{C}$ in $95 \%$ air and $5 \% \mathrm{CO}_{2}$. Once confluent, human aortic smooth muscle cells (HASMC) were dissociated using Accutase ${ }^{\circledR}$ (Innovative Cell Technologies Inc., San Diego, Calif., USA) and pelleted at $1,000 \mathrm{rpm}$ for $10 \mathrm{~min}$ prior to further passage. HASMC content was characterised as $>85 \%$ using mouse anti-human desmin (Dako M0760), mouse anti-human smooth muscle myosin heavy chain (Dako M3558) and mouse anti-human smooth muscle actin (Dako M0851)

Cells were then exposed to sequential decreases in $\mathrm{O}_{2}$ inside a sealed Minimac chamber at $37^{\circ} \mathrm{C}$ (Don Whitley Scientific, West Yorkshire, UK), incorporating an oxygen sensor to monitor levels (Analox Mini $\mathrm{O}_{2}$ DII Oxygen Analyser; Analox Sensor Technology, Stokesley, UK). Cultures were subjected to $5 \% \mathrm{O}_{2}$ for $24 \mathrm{~h}$, then $3 \% \mathrm{O}_{2}$ up to $48 \mathrm{~h}, 2 \% \mathrm{O}_{2}$ up to $72 \mathrm{~h}$ and finally $1 \% \mathrm{O}_{2}$ up to $96 \mathrm{~h}$ (Certificated BOC Gases, Surrey, UK). Controls were maintained throughout the 72 -hour period in a standard incubator at $37^{\circ} \mathrm{C}$. In addition, HASMC were maintained in serum-free medium under severe hypoxia $\left(5 \% \mathrm{CO}_{2}, 94 \% \mathrm{~N}_{2}\right.$ and $\left.1 \% \mathrm{O}_{2}\right)$ at $37^{\circ} \mathrm{C}$ for up to $48 \mathrm{~h}$. A commercially acquired cell line of primary HASMCs (ZHC-3121; TCS Cellworks Ltd., Buckingham, UK) was also run in parallel as a control for aspects of the harvesting and isolation procedures.

Lactate Dehydrogenase Cell Viability Assay

Media were assayed for lactate dehydrogenase activity with 1.5 $\mathrm{mM}$ sodium lactate, $1 \mathrm{mM} \mathrm{NAD}^{+}, 1 \mu \mathrm{M}$ diphenyliodonium chloride and PBS. The generation of NADH was followed by measuring the absorbance change at wavelength $340 \mathrm{~nm}$ over time using a Hitachi U-2010 spectrophotometer. 
Gelatin Zymography of Conditioned Media

Protein concentration was determined by Bio-Rad ${ }^{\circledR}$ protein assay (Bio-Rad Laboratories, Hertfordshire, UK). MMP were separated on $7.5 \%$ polyacrylamide resolving gel containing $1 \%$ gelatin and $4 \%$ polyacrylamide stacking gel. MMP-2/MMP-9 standards (Chemicon Europe Ltd., Chandlers Ford, UK) were used as positive controls. Electrophoresis was performed at $100 \mathrm{~V}$ with subsequent incubation at $37^{\circ} \mathrm{C}$ in development solution $(5 \mathrm{~mm}$ $\mathrm{CaCl}_{2}, 50 \mathrm{M}$ Tris- $\mathrm{HCl} \mathrm{pH}$ 7.6). After de-staining in methanol, glacial acetic acid and $\mathrm{dH}_{2} \mathrm{O}(4: 1: 5, \mathrm{v} / \mathrm{v} / \mathrm{v})$, incubation of the zymogram for $48 \mathrm{~h}$ in water afforded enhanced band resolution. Semiquantitative image analysis was carried out using Scion Imaging Software (version 4.0.2; www.scioncorp.com).

MMP-2 and HIF-1 $\alpha$ Immunoblot Analysis of Conditioned Media and Cell Lysates

Samples, standardised for protein, were loaded onto 7.5\% SDSPAGE gels, then transferred onto nitrocellulose membranes and probed using mouse monoclonal anti-human MMP-2 (Abcam Plc., Cambridge, UK), mouse monoclonal anti-human HIF-1 $\alpha$ (Novus Biologicals, Littleton, Colo., USA), mouse monoclonal anti-human VEGF or rabbit polyclonal anti-human Ets-1 (Santa Cruz Inc.) and finally polyclonal horseradish peroxidase-conjugated goat anti-mouse or swine anti-rabbit (Dako UK Ltd., Ely, UK). Proteins were visualised using an Amersham ECL Advance $^{\mathrm{TM}}$ Western blotting detection kit (GE Healthcare Life Sciences, Buckinghamshire, UK).

\section{Reverse Transcriptase PCR}

Total RNA was isolated using RNA Stat-60 (AMS-Biotechnology, Abingdon, UK). Reverse transcriptase PCR (RT-PCR) was carried out on all RNA samples extracted that had an absorbance (wavelength 260/280 $\mathrm{nm}$ ) ratio of greater than 1.4 using an Abgene ${ }^{\circledR}$ commercial kit (Thermo Fisher Scientific Ltd., Epsom, UK).

\section{Multiplex PCR}

Multiplex PCR kits were used to identify and analyse GAPDH (500 bp), MMP-1 (395 bp), MMP-3 (351 bp), MMP-7 (282 bp), MMP-9 (216 bp) and MMP-2 (192 bp) (human MMP genes set-3; Maxim Biotech Inc., San Francisco, Calif., USA); 18S (554 bp), MMP-1 (395 bp), TIMP-1 (265 bp) and membrane-type MMP (MT-MMP-1; 223 bp) (human MMP genes set-2; Maxim Biotech Inc.). The kits were used in accordance with the manufacturer's instructions.

\section{PCR Product Analysis}

All PCR amplification products were analysed by $10 \%$ agarose gel electrophoresis visualised and stained via ethidium bromide incorporation. A 100-bp DNA ladder (Maxim Biotech Ltd.) incorporating loading dye was loaded per gel to allow PCR product size identification. The gel was subjected to electrophoresis at a constant $50 \mathrm{~V}$ for $45 \mathrm{~min}$. Results were expressed as the product-tohousekeeping gene (GAPDH/18S) ratio.

\section{Data Presentation and Statistical Analysis}

Densitometric analysis was carried out using the Scion Corporation Imaging program. Statistical analyses (Student's t test and one-way ANOVA) were performed using GraphPad Prism version 4.0 for Windows (GraphPad Software Inc., La Jolla, Calif., USA). Statistical significance was indicated by $\mathrm{p}$ values less than 0.05 .

\section{Results}

Localisation and Activity Profiles of MMP in AAA

Diffuse MMP-2 immunopositivity was observed in the vascular smooth muscle cells within the region of tunica media distant from the vasa vasorum and also in inflammatory infiltrate of proximal, body and distal regions from all 36 AAA examined. Staining for MMP-2 was markedly increased in comparison to the 12 normal aortae. Immunohistochemical (expression) analysis of the 3 aneurysmal regions revealed MMP-2 to be present in all regions of the sac but particularly intense in the most dilated region, the body. Zymographic (activity) analysis of these regions demonstrated MMP-2 and MMP-9 protein to be significantly elevated in the body of the AAA wall when compared with results for the distal wall ( $\mathrm{p}<0.05$ and $\mathrm{p}<0.01$, respectively). Differences were also noted for MMP-2 protein levels between the body and proximal regions of the AAA wall ( $p<0.01$; data not shown).

\section{Distribution of HIF- $1 \alpha$ in $A A A$}

The finding of MMP-2 at sites furthest from the source of oxygen suggests a possible hypoxic activation; therefore, the presence of the global oxygen sensor, HIF- $1 \alpha$, was appraised. Intense staining for HIF- $1 \alpha$ was predominantly localised to the nuclei of cells within the tunica media and the inflammatory infiltrate of all 36 AAA analysed, in contrast to its less intense cytoplasmic localisation in 12 normal aortae. Moreover, regional localisation in AAA mirrored that of MMP-2.

\section{Distribution of Ets-1 in AAA}

In addition, immunohistochemical analysis showed a marked difference in Ets-1 immunopositivity in AAA tissue when compared to normal aorta tissue samples. The transcription factor was also localised to the nuclei of matrix cells within the tunica media and inflammatory cells of the diffuse infiltrate. The matrix cells surrounding the periphery of the vasa vasorum were negative for Ets-1 in AAA tissues.

\section{Effect of Progressive Hypoxia on the Activity of \\ HASMC MMP}

All HASMC culture supernatants were evaluated for lactate dehydrogenase presence as a function of cell viability. No NADH generation was noted from any of the normoxic or hypoxic cultures up to and including $72 \mathrm{~h}$. $\mathrm{NADH}$ production was, however, evident in supernatants from cells exposed to hypoxia for longer than $72 \mathrm{~h}$; there- 


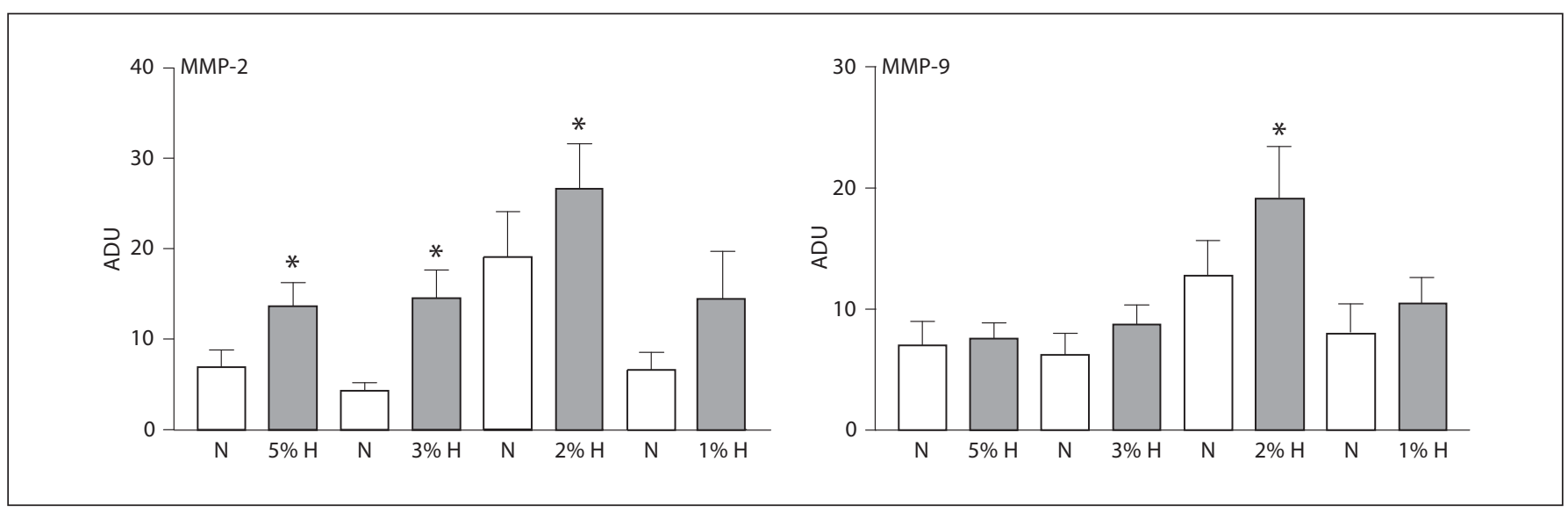

Fig. 1. Results of HASMC-conditioned media analysis for MMP-2 and MMP-9 assessed by gelatin zymography following incubation in a controlled hypoxic environment involving sequential decreases (5-1\%) in oxygen percentage over $96 \mathrm{~h}$. Data are expressed as means \pm SEM of triplicate values. ADU = Arbitrary density units; $\mathrm{N}=$ normoxia; $\mathrm{H}=$ hypoxia. ${ }^{*} \mathrm{p}<0.05$.

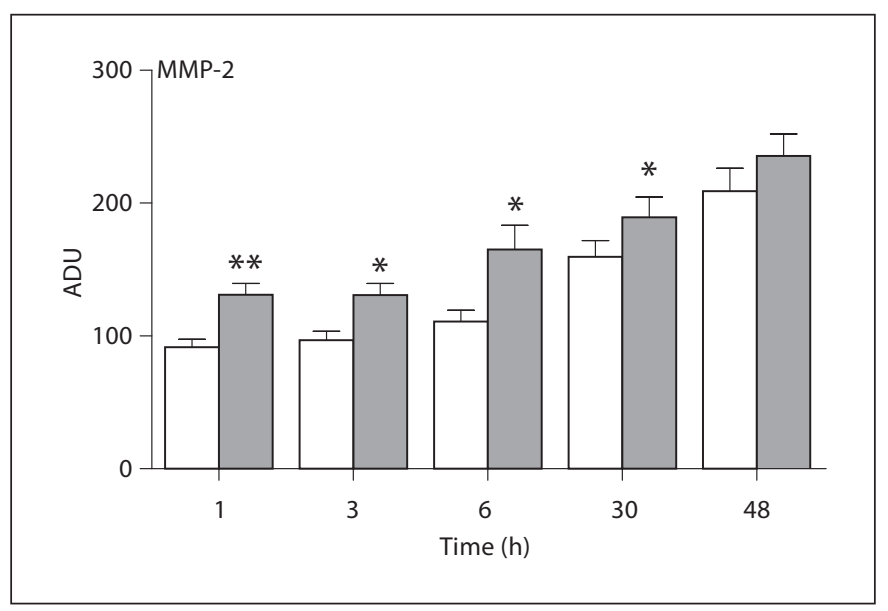

Fig. 2. Zymographic analysis of MMP-2 activity in culture supernatants from HASMC exposed to $1 \%$ hypoxia (filled bars) or normoxia (open bars) for $48 \mathrm{~h}$. Results expressed as arbitrary density units (ADU) per unit standardised total protein. Data expressed as means \pm SEM of 3 values. ${ }^{*} \mathrm{p}<0.05 ;{ }^{* *} \mathrm{p}<0.01$.

fore, evaluation was not carried out beyond this time point. THP-1 monocyte lysate served as positive and PBS as negative control.

HASMCs, after exposure to a progressive decrease in oxygen tension, responded by elevating secretion of MMP-2 and MMP-9 into culture media (fig. 1). Secretion of MMP-2 was significant within $24 \mathrm{~h}$ at $5 \% \mathrm{O}_{2}$ $(\mathrm{p}<0.05)$ and was sustained after decreasing the oxygen tension to $3 \%$ up to $48 \mathrm{~h}(\mathrm{p}<0.01)$. The secretion of MMP-2 was further up-regulated upon another decrease $\left(2 \% \mathrm{O}_{2}\right)$ and exposure for another $24 \mathrm{~h}(\mathrm{p}<0.05)$. Increased MMP-9 secretion occurred only after 3 sequential decreases in oxygen tension terminating at $2 \%$ $\mathrm{O}_{2}(\mathrm{p}<0.05)$. The observed increase by $72 \mathrm{~h}$ in secreted MMP-2 and MMP-9 under normoxic conditions might be explained by an increase in constitutive expression possibly enhanced by the beginning of nutrient depletion-induced stress.

\section{Effect of Severe Hypoxia on the Activity of HASMC $M M P$}

Subsequently, we wished to further investigate hypoxia as a driving force behind elevated HASMC MMP secretion and assess the induction times of this response to severe hypoxia $\left(1 \% \mathrm{O}_{2}\right)$. In this instance, cells were maintained in serum-free media to rule out foetal calf serum as a potential confounding factor.

Results of gelatin zymography evaluation revealed that hypoxia for $1 \mathrm{~h}$ led to a significant increase in secreted pro and active MMP-2 species $(\mathrm{p}<0.01)$ (fig. 2). Significant increases were also noted at $3 \mathrm{~h}(\mathrm{p}<0.05)$, at $6 \mathrm{~h}$ $(\mathrm{p}<0.05)$ and at $30 \mathrm{~h}(\mathrm{p}<0.05)$. Analysis at $48 \mathrm{~h}$ showed sustained elevations, but no significance was found. The elevations for MMP-2 within conditioned media between the normoxia time points were not found to be significant. No significant differences were noted for MMP-9 secretion during exposure to $1 \% \mathrm{O}_{2}$ for $48 \mathrm{~h}$ (data not shown). 

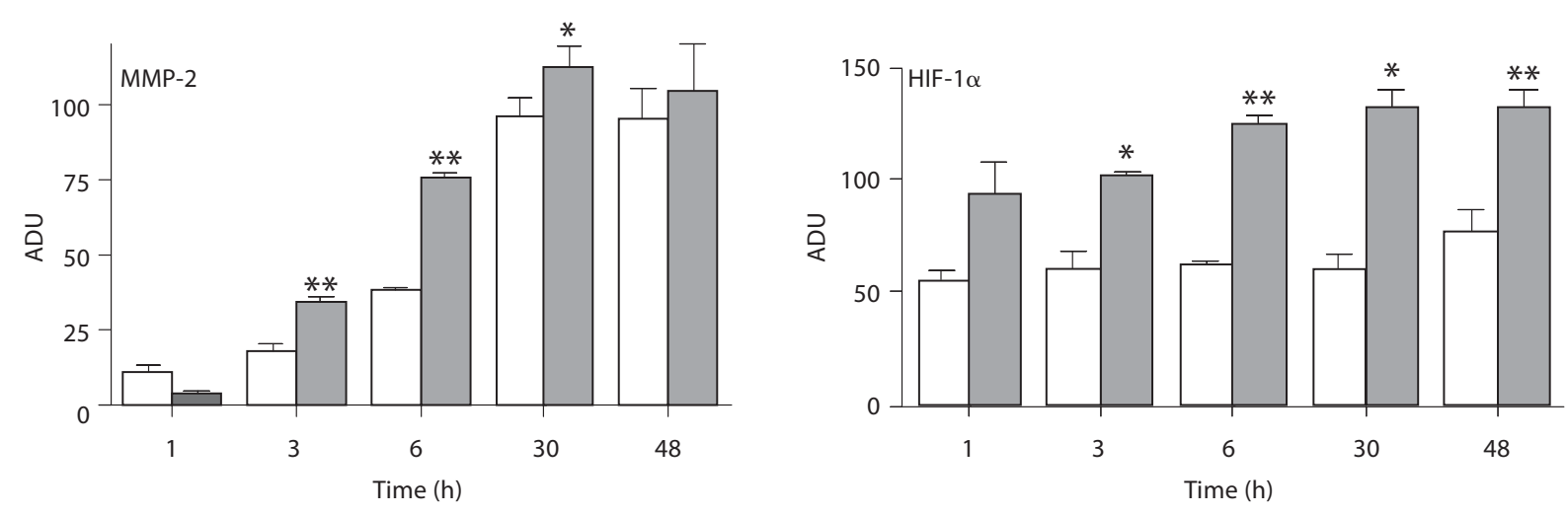

Fig. 3. Levels of MMP-2 in conditioned media and HIF-1 $\alpha$ protein in total HASMC lysate after exposure to hypoxia (1\%; filled bars) or normoxia (open bars) for $48 \mathrm{~h}$ assessed by immunoblotting. Results expressed as arbitrary density units (ADU) per unit standardised total protein. Data expressed as means \pm SEM of 3 values. ${ }^{*} \mathrm{p}<0.05 ;{ }^{* *} \mathrm{p}<0.01$.

Clearly, hypoxia drives changes in MMP exportation from the HASMC in vitro. As mentioned earlier, immunohistochemistry results reveal possible co-localisation of HIF- $1 \alpha$ and MMP-2. Thus, we examined the hypoxiaexposed HASMC total lysate for HIF- $1 \alpha$ and conditioned media for MMP-2 by immunoblotting (fig. 3).

\section{Effects of Hypoxia on HASMC Transcription Factor Expression}

MMP-2 immunoblot analysis corroborated that MMP-2 protein was present in the HASMC culture supernatant. At the 1-hour time point there was no significant difference in levels of MMP-2 protein between the hypoxic and normoxic samples, but after 3,6 and $30 \mathrm{~h}$, a significant rise $(\mathrm{p}<0.01, \mathrm{p}<0.01$ and $\mathrm{p}<0.05$, respectively) in protein levels was evident. The 48 -hour time point also showed an increase in MMP-2 protein, but this was not statistically significant. Significant elevations were observed between the 1- and 30-hour normoxia time points $(\mathrm{p}<0.01)$.

HIF-1 $\alpha$ immunoblot analysis established the presence of increased HIF-1 $\alpha$ in total cell lysate from HASMCs over $48 \mathrm{~h}$ of hypoxia. After $1 \mathrm{~h}$ of hypoxia, there was an increase in levels of HIF-1 $\alpha$ protein between the hypoxic and normoxic samples, although not considered statistically significant, but after $3,6,30$ and 48 h of hypoxia, a significant rise was demonstrated $(\mathrm{p}<0.05, \mathrm{p}<0.01$, $\mathrm{p}<$ 0.05 and $\mathrm{p}<0.01$, respectively). Results of Ets-1 Western blot showed significant induction at $1 \mathrm{~h}(\mathrm{p}<0.01)$, sustained at $3 \mathrm{~h}(\mathrm{p}<0.01)$ and $6 \mathrm{~h}(\mathrm{p}<0.05)$ (data not shown).
A target gene for HIF-1 $\alpha$, VEGF, was also evaluated by Western blotting and was found to be significantly upregulated at $1 \mathrm{~h}(\mathrm{p}<0.05), 3 \mathrm{~h}(\mathrm{p}<0.05), 6 \mathrm{~h}(\mathrm{p}<0.05)$ and sustained to $48 \mathrm{~h}(\mathrm{p}<0.01)$ (data not shown).

Multiplex PCR analysis revealed significant transcriptional up-regulation of MMP-7 ( $\mathrm{p}<0.001)$, MMP-1 ( $<<$ $0.01)$, MT-MMP-1 $(\mathrm{p}<0.05)$ and TIMP-1 $(\mathrm{p}<0.01)$ as a consequence of exposure to hypoxia for up to $48 \mathrm{~h}$ (fig. 4). No significant transcriptional up-regulation of MMP-3 was observed. Results for MMP-9 and MMP-2 showed evidence of increased transcription for the hypoxic cultures when compared with normoxia, although no statistical significance was noted.

\section{Discussion}

A role for hypoxia in the early stages of AAA development is strengthened by the finding that MMP-2 is secreted in highest levels from hypoxic HASMCs, and the transcription factor HIF- $1 \alpha$ co-localises with high expression of MMP to the tunica media and pro-inflammatory infiltrate. Although suggestive of a causal relationship, this is not demonstrated definitively. Initially we showed that HIF-1 $\alpha$ expression is greater in regions of the AAA sac compared to normal non-aneurysmal control tissue, these results corroborate those of $\mathrm{Hu}$ et al. [23], who have shown similar HIF-1 $\alpha$ expression in the AAA.

Earlier studies suggested that intraluminal thrombus present in approximately $75 \%$ of all cases of AAA attenu- 
Fig. 4. Levels of MMP mRNA from HASMC lysate total mRNA. The HASMC in culture were exposed to hypoxia or normoxia for $72 \mathrm{~h}$ and were assessed using multiplex PCR. The MMP mRNA results are expressed as a function of GAPDH in arbitrary density units (ADU). Data are expressed as means \pm SEM of triplicate values. ${ }^{*} \mathrm{p}<0.05$; $^{* *} \mathrm{p}<0.01$; $^{* *} \mathrm{p}<0.001$.

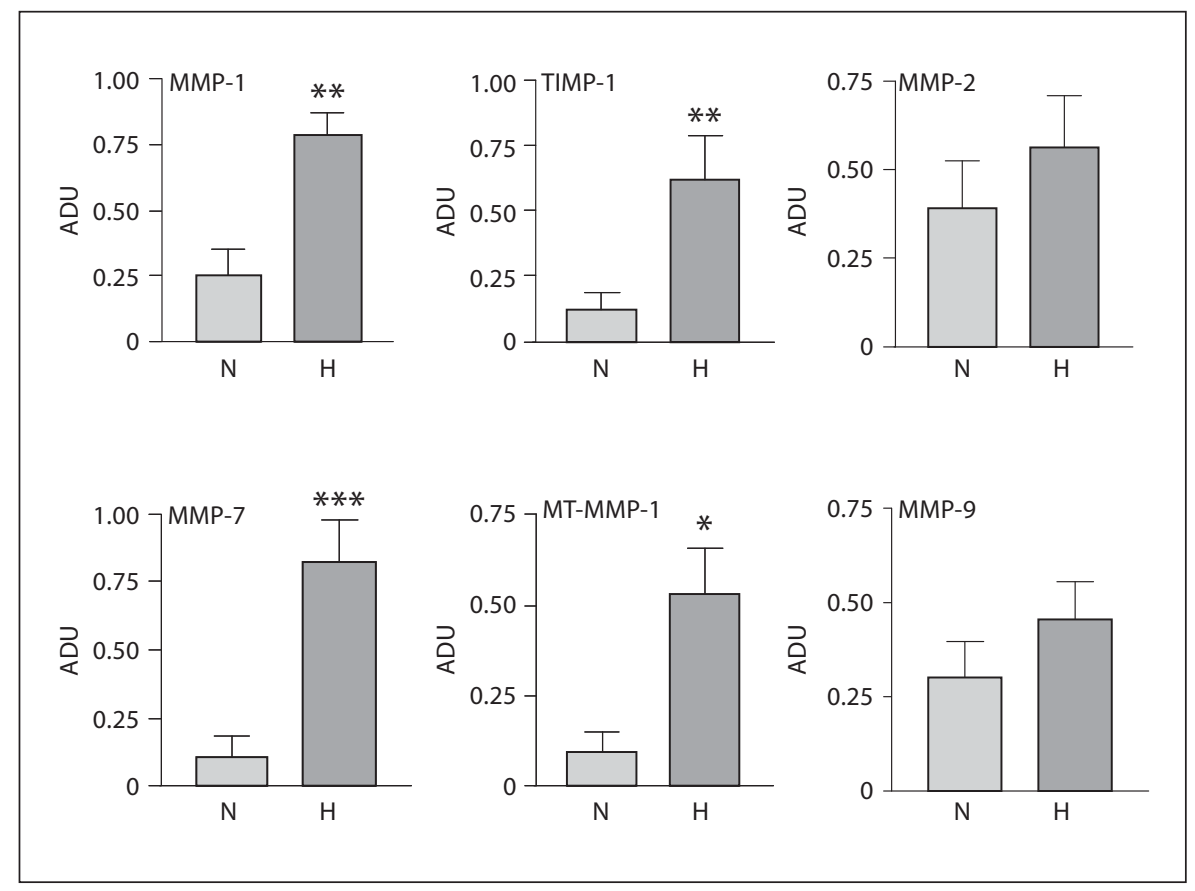

ates oxygen diffusion to the AAA wall leading to localised hypoxia $[13,14]$. We wished to investigate and substantiate the hypothesis that MMP up-regulation in the AAA is directly or indirectly attributed to HIF- $1 \alpha$ induction as a function of hypoxia. Our findings suggest that smooth muscle cells within the tunica media also respond to mild hypoxic stress $\left(5 \% \mathrm{O}_{2}\right)$ by secreting MMP-2, strengthening the hypothesis that localised hypoxia could be an initiating factor in the pathogenesis of AAA. More recently, Sun et al. [25] designed a numerical model of oxygen transport in AAA with intraluminal thrombus that demonstrated $\mathrm{O}_{2}$ levels of $\leq 1 \%$ within the thickest regions of the thrombus. This, in addition to our results (fig. 1), led us to evaluate the effect of more severe hypoxia (1\%) on MMP secretion.

Interestingly, although MMP-2 secretion was significantly increased during the 5-2\% $\mathrm{O}_{2}$ HASMC experiment, MMP-9 was only significantly increased at $2 \% \mathrm{O}_{2}$ and undetected during $48 \mathrm{~h}$ of hypoxia at $1 \% \mathrm{O}_{2}$, suggesting the driving force behind MMP-9 exportation is a sustained sequential decrease in $\mathrm{O}_{2}$ over time.

Our findings relating to MMP-2 (confirmed by both zymography and immunoblotting) indicated significant secretion into conditioned media from normoxic cultures that could be a combination of constitutive expression and antibody binding to fragments of MMP-2 or enzyme doublets. Interestingly, our results indicate the lev- els of HIF-1 $\alpha$, Ets-1 and VEGF rise earlier than MMP-2. This could be explained by hypoxia being sensed in the first instance by the global oxygen sensor HIF resulting in the stabilisation of the HIF- $1 \alpha$ subunit, nuclear translocation and subsequent binding to the hypoxia response element of VEGF and Ets-1, thus resulting in the up-regulation of these target genes. Latterly, MMP-2 is up-regulated by Ets-1, hence the delayed rise observed in the immunoblot for MMP-2.

Similarities in the pathogenesis profile of the aneurysm with other disease states are evident. Of particular interest, in view of our hypothesis, hypoxia and HIF-1 $\alpha$ are responsible for modulating MMP in other research areas [16-18, 26]. For instance, Notari et al. [26] showed that hypoxia can down-regulate pigment epithelium-derived factor through proteolytic degradation by MMP-2 and MMP-9.

A hallmark of aneurysmal disease, the inflammatory infiltrate, was extensively immunopositive for HIF-1 $\alpha$ in all AAA samples, particularly apparent in the proximal and body regions. The fact that the HIF- $1 \alpha$ immunopositivity was predominantly localised to the nucleus in all AAA tissue examined but localised to the cytoplasm in normal aortae indicates that nuclear translocation has occurred, a prerequisite of hypoxia-induced transcription. We have shown transcriptional upregulation of MMP-1, MT-MMP-1 and TIMP-1 in HASMCs in re- 
sponse to hypoxia which are known to be up-regulated and contribute towards AAA development [20, 27, 28]. We also found substantial transcriptional up-regulation of MMP-7. Although its involvement in AAA pathogenesis is largely unknown, immunohistochemical analysis of pathological aortae indicated differences in the distribution of this factor from normal aorta [29]. Our finding of significant up-regulation in MMP-7 transcription potentiated by hypoxia further corroborates a role for this factor in the development of AAA.

We know that HIF- $1 \alpha$ targets certain genes by directly binding to hypoxia response elements of vegf, glut-1 and other gene promoters. It has also been shown that VEGF, MMP-1, MMP-3 and MMP-13 are similarly increased in AAA tissue through an unknown mechanism but possibly via a signalling cascade involving HIF- $1 \alpha$ and NF- $\mathrm{KB}[23,30,31]$.

The expression of MMP-2, HIF- $1 \alpha$ and Ets-1 remains highest at the distal and body regions of the AAA that are taken to represent areas of more advanced aneurysm development. It is possible that these observed differences could be due to a change in blood-flow dynamics. During aortic expansion, unsteady three-dimensional blood flow causes additional shear strain on the distal portion of the aneurysm [32].

In order to further explore the tissue markers of hypoxia, we decided to investigate the AAA tissue samples for the transcription factor, Ets-1. Hypoxia has been shown to induce Ets-1 via the activity of HIF-1 $\alpha$ [19]; therefore, we surmise that Ets-1 could be involved in the signalling cascade, terminating in MMP up-regulation observed in our hypoxia studies. More recently, MMP-2 and MMP-9 were found to be target genes for Ets-1 [33].
Tissues from AAA were found to display a marked increase in immunopositivity for both Ets-1 and HIF-1 $\alpha$ transcription factors, when compared with the results obtained for normal aortic tissue. Both factors localise to the vascular smooth muscle cells and inflammatory infiltrate, with a predominance of expression observed in the medial layer of the aneurysm wall. In addition to this, MMP2 is also localised to the same regions. Moreover, in regions where the highest MMP-2 expression was noted, heightened HIF-1 $\alpha$ and Ets-1 was also evident, namely in the tunica media distant from the vasa vasorum. The body of the AAA sac where the lumen is most dilated is also the region with most intense MMP-2, HIF-1 $\alpha$ and Ets- 1 expression. AAA tissue immediately flanking vasa vasorum vessels were the only regions found to be negative for Ets-1, which indicates that oxygen diffusion from these vessels is insufficient in protecting aortic tissue undergoing extensive matrix remodelling from tissue hypoxia.

Work is ongoing and as this study would benefit from examining the effect of hypoxia on endothelial cell HASMC co-culture, also multiple immunohistochemical analysis of the co-cultures and tissues for HIF-1 $\alpha$, Ets-1 and MMP would significantly add to the body of knowledge.

In conclusion, hypoxia signalling is markedly apparent in the AAA and potentially plays a primary role in the disease process.

\section{Acknowledgments}

The authors thank the Vascular Surgical Forum, Royal United Hospital, Bath for financial support.

\section{References}

1 Davis M, Taylor PR: Endovascular infrarenal abdominal aortic aneurysm repair. Heart 2008;94:222-228.

$\checkmark 2$ Freestone T, Turner RJ, Higman DJ, Lever MJ, Powell JT: Inflammation and matrix metalloproteinases in the enlarging abdominal aortic aneurysm. Arterioscler Thromb Vasc Biol 1995;15:1145-1151.

-3 Heughan C, Niinikoski J, Hunt TK: Oxygen tensions in lesions of experimental atherosclerosis of rabbits. Atherosclerosis 1973;17: 361-367.

4 Zemplenyi T, Crawford DW, Cole MA: Adaptation to arterial wall hypoxia demonstrated in vivo with oxygen microcathodes. Atherosclerosis 1989;76:173-179.
5 Crawford DW, Blankenhorn DH: Arterial wall oxygenation, oxyradicals, and atherosclerosis. Atherosclerosis 1991;89:97-108.

6 Lee ES, BauerGE, Caldwell MP, Santilli SM: Association of artery wall hypoxia and cellular proliferation at a vascular anastomosis. J Surg Res 2000;91:32-37.

7 Santilli SM, Wernsing SE, Lee ES: Transarterial wall oxygen gradients at a prosthetic vascular graft to artery anastomosis in the rabbit. J Vasc Surg 2000;31:1229-1239.

-8 Martin JF, Booth RF, Moncada S: Arterial wall hypoxia following thrombosis of the vasa vasorum is an initial lesion in atherosclerosis. Eur J Clin Invest 1991;21:355-359. $\checkmark 9$ Bjornheden $\mathrm{T}$, Levin $\mathrm{M}$, Evaldsson $\mathrm{M}$, Wiklund O: Evidence of hypoxic areas within the arterial wall in vivo. Arterioscler Thromb Vasc Biol 1999;19:870-879.

10 Vorp DA, Federspiel WJ, Webster MW: Does laminated intraluminal thrombus within abdominal aortic aneurysm cause anoxia of the aortic wall? J Vasc Surg 1996;23:540-541.

11 Vorp DA, Mandarino WA, Webster MW, Gorcsan J: Potential influence of intraluminal thrombus on abdominal aortic aneurysm as assessed by a new non-invasive method. Cardiovasc Surg 1996;4:732-739. 
-12 Vorp DA, Wang DH, Webster MW, Federspiel WJ: Effect of intraluminal thrombus thickness and bulge diameter on the oxygen diffusion in abdominal aortic aneurysm. J Biomech Eng 1998;120:579-583.

-13 Vorp DA, Lee CP, Wang DH, Makaroun MS Nemoto EM, Ogawa S, Webster MW: Association of intraluminal thrombus in abdominal aortic aneurysm with local hypoxia and wall weakening. J Vasc Surg 2001;34:291299.

-14 Choke E, Cockerill GW, Dawson J, Chung YL, Griffiths J, Wilson RW, Loftus IM, Thompson MM: Hypoxia at the site of abdominal aortic aneurysm rupture is not associated with increased lactate. Ann NY Acad Sci 2006;1085:306-310.

-15 Coutard M,Touat Z, Houard X, Leclercq A, Michel J-B: Thrombus versus wall biological activities in experimental aortic aneurysms. J Vasc Res 2010;47:355-366.

-16 Pufe T, Lemke A, Kurz B, Petersen W, Tillman B, Grodzinsky AJ, Mentlein R: Mechanical overload induces VEGF in cartilage discs via hypoxia inducible factor. Am J Pathol 2004; 164:185-192.

- 17 Yamaguchi A, Tojyo I, Yoshida H, Fujita S: Role of hypoxia and interleukin-1 $\beta$ in gene expressions of matrix metalloproteinases in temporomandibular joint disc cells. Arch Oral Biol 2005;50:81-87.

$\checkmark 18$ Krishnamachary B, Berg-Dixon S, Kelly B, Agani F, Feldser D, Ferreira G, Iyer N, LaRusch J, Pak B, Taghavi P, Semenza G: Regulation of colon carcinoma cell invasion by hypoxia-inducible factor 1 . Cancer Res 2003; 63:1138-1143.

19 Oikawa K, Abe M, Kurosawa H, Hida W, Shirato K, Sato Y: Hypoxia induces transcription factor ETS-1 via the activity of hypoxiainducible factor-1. Biochem Biophys Res Commun 2001;289:39-43.
20 Newman KM, Jean-Claude J, Li H, Scholes JV, Ogata Y, Nagase H, Tilson DW: Cellular localisation of matrix metalloproteinases in the abdominal aortic aneurysm wall. J Vasc Surgery 1994;20:814-820.

21 Hellwig-Bürgel T, Rutkowski K, Metzen E, Fandrey J, Jelkmann W: Interleukin-1 $\beta$ and tumor necrosis factor- $\alpha$ stimulate DNA binding of hypoxia-inducible factor-1. Blood 1999;94:1561-1567.

22 Hamano K, Li TS, Takahashi M, Kobayashi T, Shirasawa B, Ito H, Zempo N: Enhanced tumour necrosis factor- $\alpha$ expression in small sized abdominal aortic aneurysms. World J Surg 2003;27:476-480.

$23 \mathrm{Hu}$ XH, Yang J, Liu CW, Zhang XS, Zhang Q The expression and significance of hypoxiainducible factor- $1 \alpha$ and related genes in abdominal aorta aneurysm. Zhonghua Wai Ke Za Zhi 2004;42:1509-1512.

24 Han YP, Tuan TL, Wu H, Hughes M, Garner WL: TNF- $\alpha$ stimulates activation of proMMP2 in human skin through NFKB mediated induction of MT1-MMP. J Cell Sci 2000 114:131-139.

25 Sun N, Leung JH, Wood NB, Wright AR, Cheshire N, Hughes AD, Thom SAM, Xu XY: Numerical modelling of oxygen transport in a human abdominal aortic aneurysm with intraluminal thrombus. J Biomechanics 2007;40:S263.

26 Notari L, Miller A, Martinez A, Amaral J, Ju M, Robinson G, Smith LE, Becerra SP: Pigment epithelium-derived factor is a substrate for matrix metalloproteinase type 2 and type 9: implications for down regulation in hypoxia. Invest Opthalmol Vis Sci 2005;46: 2736-2747.
27 Crowther M, Goodall S, Jones JL, Bell PRF, Thompson MM: Increased matrix metalloproteinase-2 expression in vascular smooth muscle cells cultured from abdominal aortic aneurysms. J Vasc Surg 2000;32:575-583.

28 Armstrong PJ, Johanning JM, Calton WC Jr, Delatore JR, Franklin DP, Han DC, Carey DJ, Elmore JR: Differential gene expression in human abdominal aorta: aneurysmal versus occlusive disease. J Vasc Surg 2002;35:346355.

29 Borges LF, Touat Z, Leclercq A, Zen AA, Jondeau' G, Franc B, Philippe M, Meilhac O, Gutierrez PS, Michel JB: Tissue diffusion and retention of metalloproteinases in ascending aortic aneurysms and dissections. Hum Pathol 2009;40:306-313.

30 Knox JB, Sukhova GK, Whittemore AD, Lippy P: Evidence for altered balance between matrix metalloproteinases and their inhibitors in human aortic diseases. Circulation 1997;95:205-212.

-31 Tromp G, Gatalica Z, Skunca M, Berguer R, Siegel T, Kline RA, Kuivaniemi H: Elevated expression of matrix metalloproteinase-13 in abdominal aortic aneurysms. Ann Vasc Surg 2004;18:414-420.

32 Taylor TW, Yamaguchi T: Three-dimensional simulation of blood flow in an abdominal aortic aneurysm - steady and unsteady flow cases. J Biomech Eng 1994;116:89-97.

-33 Okuducu AF, Zils U, Michaelis SA, Michaelides S, von Deimling A: Ets-1 is up-regulated together with its target gene products matrix metalloproteinase-2 and matrix metalloproteinase-9 in atypical and anaplastic meningiomas. Histopathology 2006;48: 836-845. 